\title{
The Method of Decomposition of Architectural Objects for the preparation of 3D Virtual Models and Replication
}

\section{Jerzy Montusiewicz ${ }^{1 *}$, Marcin Barszcz ${ }^{1}$, Krzysztof Dziedzic ${ }^{1}$ Tomasz Nowicki ${ }^{1}$}

1 Department of Computer Science, Faculty of Electrical Engineering and Computer Science, Lublin University of Technology, Nadbystrzycka 36B, 20-618 Lublin, Poland

* Corresponding author's e-mail: j.montusiewicz@pollub.pl

\begin{abstract}
Three-dimensional (3D) printing of historic architectural objects reduces the entire digital model by up to 200 times. With this scaling of the digital 3D model, many important architectural and decorative details are lost, and some elements lose their stiffness. Printed 3D models are now used to create specialised museum exhibitions that allow visitors to get to know them kinesthetically. This ability to touch objects applies not only to visually impaired people, but to all interested visitors. The paper describes the preparation of a digital 3D model (D3DM) dedicated to $3 \mathrm{D}$ printing by decomposing the real model into sub-models and using different scaling values for individual elements. The practical part presents three-dimensional modelling of historic architectural objects of Lublin and their replicas made on 3D printers in the Fused Filament Fabrication (FFF) technology. Virtual models designed in this way retain important details of objects and are also scalable as a whole, which allows for obtaining printed objects of various dimensions.
\end{abstract}

Keywords: 3D modelling procedure; 3D printing; scalability of architectural models; object replication; cultural heritage

\section{INTRODUCTION}

Creating a digital 3D model (D3DM) of various museum objects has become a fairly standard activity of many museums, which by placing them on their websites aim to attract potential tourists to visit their facilities [1]. Such activities are also aimed at preventing the exclusion of people who, for various reasons (financial, travel safety, disability, and recently the Covid-19 coronavirus pandemic), cannot visit the exhibition in a traditional form. Thanks to modern technologies of 3D computer graphics, virtual models of large objects are also created, such as: architectural monuments, models of existing historic cities or ruins of ancient cities uncovered as a result of archaeological works $[2,3]$. Such 3D models can be presented either in the form of interactive shows or conducted in the world of virtual or augmented reality [4].
Preparation of three-dimensional models also allows the use of rapid prototyping technology to obtain printed 3D models. It turns out, however, that in the case of 3D printing of historic architectural objects, there are unexpected problems due to the fact that such objects are reduced by up to 200 times during replication. Such D3DM rescaling leads to the loss of many important architectural and decorative details, and for some elements their stiffness is lost. Therefore, such models will not be suitable for creating specialised museum exhibitions that allow visitors to get to know them kinesthetically. The possibility of taking an object in your hands and touching it allows to get to know them better and not only concerns people with visual impairment $[5,6]$, but all interested visitors. Direct contact with such a three-dimensional model also allows for remembering it better [7], and is also a more attractive form for the target audience [8]. 
The goal of the study is:

- Description of the method of decomposition of real architectural objects for the preparation of virtual 3D models for 3D printing.

- Execution of exemplary 3D models of Lublin's monuments and their 3D printing on replicators working in the Fused Filament Fabrication (FFF) technology.

\section{STUDY BACKGROUND}

Creation of virtual models of architectural objects can be realised both with the use of photogrammetry [9] and terrestrial 3D laser scanning $[10,11]$. It turns out, however, that for the purposes of 3D printing, such models have too large dimensions of even several dozen MB, moreover, they have small surface discontinuities (especially at the wall joints), which are not visible during their digital viewing, but they do not meet the socalled watertight condition. This ailment means that layered models e.g. in the format .stl, which are necessary for $3 \mathrm{D}$ printing, cannot be generated.

The historic buildings are characterised by specific spatial arrangements, which make them adhere to architectural styles defined by art historians. In addition, the presence of decorative details gives the shapes of the objects often quite complicated surfaces, which makes their 3D modelling difficult to automate. The difference in the size of individual details in relation to the overall dimensions of the building is so great that the linear scaling of the object as a whole cannot be used, because details of a significantly small size will be lost.

In the available literature, two fundamental approaches to generating three-dimensional models of historic buildings can be found. The first is the use of various reverse engineering methods, which is not the subject of this work, and the second are manual modelling methods that can also be applied to the reconstruction of objects that no longer exist. In [12] the authors, by using the 3DSMax program, made a virtual model of the Parochial Cathedral of St. Mary of the Perpetual Assistance (Tarnopol, Ukraine), completely destroyed in 1954. This model was linearly scaled using the Cura program and printed on a 3D printer. A similar approach can be found in [13], in which threedimensional modelling of the Iran National Bank building (Cinema4D program) was performed, and then, using the Netfabb software, an optimised model was prepared for 3D printing of a fragment of the facility's front end. In both works, the authors did not delve into the issues of adapting the D3DMs for printing, did not provide the procedure used, and the obtained prints were characterised by the loss of some architectural elements. The scheme of D3DM generating activities shown in [12] did not concern the problem of modelling the architectural details of the object.

Another approach is the subjective deformation of an object at the stage of 3D modelling, so that selected elements are more exposed at the expense of others. This action is called a caricature approach, which results in a 3D copy that differs from the original due to exaggeration of certain details. A report on website [14] shows a 3D print of the St Joseph's Cathedral (Sioux Falls, South Dakota, USA). As before, no information about the procedure in the modelling process was provided.

Many interesting examples of various architectural objects printed in 3D technology can also be found on website [15]. The author of the report points out, however, that individual authors used an individual approach to the modelling process to create three-dimensional models. Some created models with a lot of details that were lost during printing, others reduced architectural details at the stage of creating a 3D model, others decided to divide the object into disjoint elements that had to be glued together only after 3D printing (this approach can also be found in work [16]). According to reports posted on another website [8], the creation of an accurate 3D model of an architectural object, using the traditional approach, may take as long as 6 to 12 months, and with computer modelling, thanks to the use of 3D printing, from 2 to 3 months. According to [17], in practice the time saving amounts to 40 to $75 \%$.

The information collected from research and internet sources shows that the subject of digital three-dimensional modelling of architectural objects oriented to the preparation of models for 3D printing appears sporadically, although the technology of additive creation of 3D models is becoming more and more available and cheaper. Despite the fact that there are examples of 3D printing of various known objects from the world, there is no access to the developed procedures, which would allow, on the one hand, to standardise the designer's activities and, on the other hand, to optimise them. It seems that the introduction of elements creating good practice in such 
modelling will improve the activities and contribute to the organisation of the existing knowledge on this subject.

\section{MATERIALS AND METHODS}

The process of creating D3DMs of architectural objects requires knowledge both in the area of architecture, construction, as well as available computer programs for three-dimensional modelling and 3D printing technology. Based on the authors' experience so far, it appears that the team for the preparation of virtual models are based on people with knowledge in the field of computer technologies of 3D graphics and printing. Information on the architectural details of the objects can be obtained during specialist consultations.

The sizes of historic architectural objects as a whole take values counted in tens of meters, which with the dimensions of individual decorative elements (which often determine the architectural style and the uniqueness of a monument) with dimensions of only a few to several centimeters (e.g. window recess depth, stair height, lattice thickness or cornice depth) creates a huge span. Thus, the dimensions vary by two and sometimes three orders of magnitude, which, if scaled to the size of the working space of a typical 3D printer, usually no more than $30-40 \mathrm{~cm}$ (for each dimension) would result in the loss of many details. Such a printed model would not meet the expectations and would not be suitable for creating exhibits for the blind.

The D3DM design procedure prepared consists in the use of the decomposition of the actual architectural model and the separation of submodels that will differ in both the detail of the elements of the objects and the adopted scale of mapping. The procedure is multi-level and basically consists of three levels:

- Level 1 (introduction level) - collecting historical and factual information about a historic architectural object, selection of software and tools for 3D modelling and data about a replicator to make real three-dimensional models.

- Level 2 (model decomposition) - assigning individual elements of objects to sub-models and selecting the mapping scale for the XYZ axes.

- Level 3 (3D modelling and printing) - virtual execution of the object, 3D printing simulation (model testing) and printing the real model.
Level 1 - The introduction level basically consists of three different activities:

- Collecting information about the object - descriptions, sketches, plans, photos, videos and sometimes 3D scans. This information makes it possible to determine the historical epoch of the object, the reconstructions and conversions performed, as well as its dimensions. This information makes it possible to decide the historical period of the object to be modelled.

- Selection of software and tools for three-dimensional modelling. The result of this action is the selection of a D3DM design program and preparation of a programming environment that will allow to increase the efficiency of the modelling process (defining design layers, tool palettes and predefining basic tools supporting the modelling: tracking characteristic points, types of scene viewing and ways of enlarging/reducing it).

- Collection of data about the 3D printer. Information on the accuracy of printing (the usual layer thicknesses are $0.2-0.3 \mathrm{~mm}$ ) and the size of the working space (the size of $300 \times 300 \times 400$ $\mathrm{mm}$ is considered a large space) will allow the calculation of the scale value for individual elements designed. Data on 3D printing technology will allow for proper location of D3DMs in the working space to minimise the number of generated supports $[18,19]$. Currently, the most popular 3D printing technology is Fused Deposition Modelling (FDM) [20] with its variant - FFF, due to the fact that the obtained objects are light, stiff, resistant to damage and relatively cheap, and the latest solutions allow the printing of coloured objects.

Level 2 - the level of model decomposition leads to the assignment of individual elements of the objects to separate sub-models and the selection of the mapping scale for the XYZ axis.

- Sub-model 1 includes the elements forming the basic body of the object consisting of the outer walls of the structure, buttresses and the roof. Such a sub-model determines the overall size of the object in most cases.

- Sub-model 2 consists of architectural elements such as: portals, window niches, stairs, attics, turrets, pinnacles. Such elements, quite large in size, are created by cutting from sub-model 1 or by adding new objects (solids) to this model.

- Sub-model 3 includes decorative elements (e.g. cornices, pilasters) and small structural elements (e.g. window frames, gratings, window sills, handrails on stairs). 
Level 3 - the three-dimensional modelling and 3D printing level includes three activities.

- Preparation of a digital model of the object. The previous experience of the authors leads to the application of the principle not to create $3 \mathrm{D}$ models that contain elements made using surface objects in combination with solid objects. The model of the object is made using previously selected scales for individual architectural elements. Modelling sometimes requires the design of additional elements that will strengthen flaccid architectural structures, e.g. a lantern (baroque element) crowning the roof dome of the city gate tower built in the Gothic style (Fig. 1a). The columns forming the openwork structure (Fig. 1b) supporting the small dome were reinforced by introducing the cylinder into the inner space (Fig. 1c).

- 3D printing simulation (model testing). This action allows for a virtual check if the digital 3D model has been properly designed, but also allows to calculate the printing time of the object with the introduced parameters of the 3D replicator (thickness of a single layer, type of filling the internal spaces of the model, Fig. 2a and their density). The simulation process can be performed for different final dimensions of the printed model, as well as for different positions of the object in the working space [18], which will affect the generated supports of the printed surfaces as well as the quality (smoothness) of the final surface.

- Printing the real three-dimensional model. The end of the 3D model printing process by the replicator does not end the activities, because, regardless of the printing technology used, many finishing activities must be performed. The raw model should be cleaned, Fig. 2b, supports should be removed (mechanically or by dissolving them), with some technologies the model should be fixed by resin treatment or irradiation. In some cases, the printed elements of the model should be assembled as a whole. Performing all these activities allows only to obtain a utility model, Fig. 2c.

The developed procedure was used to prepare digital 3D models of selected architectural monuments of Lublin. The modelling was performed in AutoCAD 2019 by Autodesk [21], which was used, among others, for the design of large historic buildings [22], digital reconstruction of historical armor [23], cultural heritage sites [24, $25]$, etc. The device was selected for 3D printing MakerBot Replicator Z18 working in FFF technology with a working space amounting to: $300 \times 300 \times 420 \mathrm{~mm}$. The following values of the main printing parameters were adopted: layer thickness $-0.2 \mathrm{~mm}$, object filling density $-10 \%$, filling pattern - diamont, generation of supports, chamber temperature $-30^{\circ} \mathrm{C}$. PLA plastic with a filament diameter of $1.75 \mathrm{~mm}$ was used.

\section{RESULTS}

\section{The three-dimensional model of the Holy Ghost church}

The Holy Ghost church is an existing facility, which is currently in a compact arrangement (there are other buildings adjacent to it). Initially, it was a hospital temple built at the beginning of the 15th

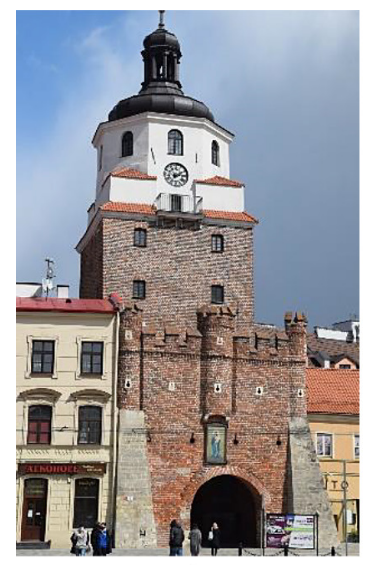

a)

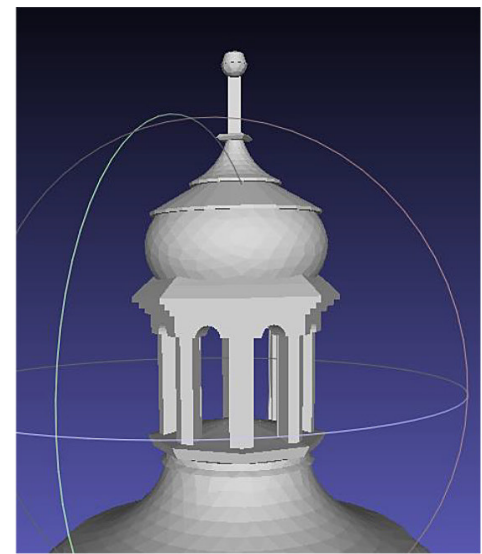

b)

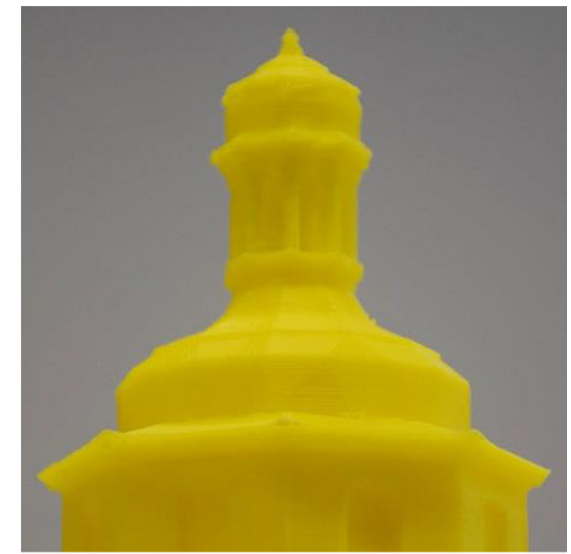

c)

Fig. 1. Cracow Gate, 16th century, Lublin, Poland: a) a photo of the modern state, b) a virtual model of the so-called lantern without stiffening, c) 3D print - structure after stiffening 


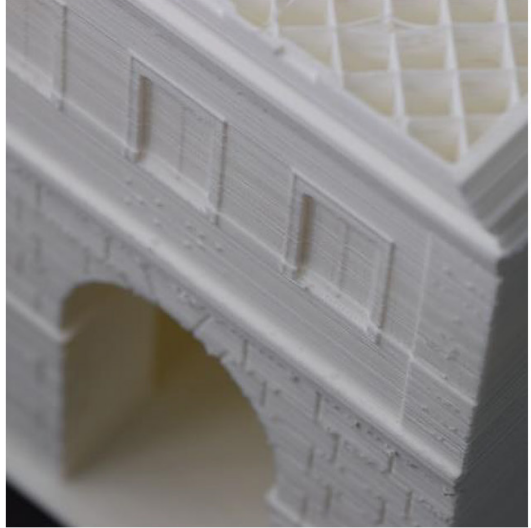

a)

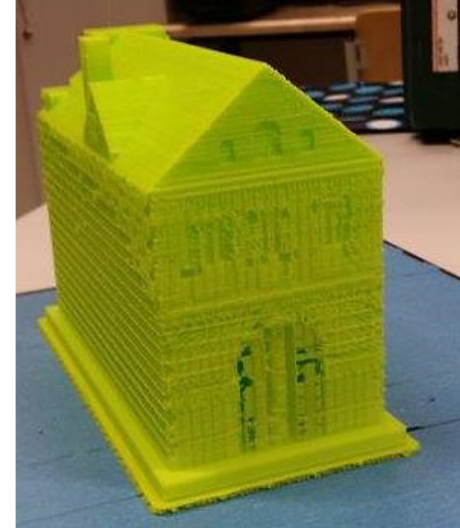

b)

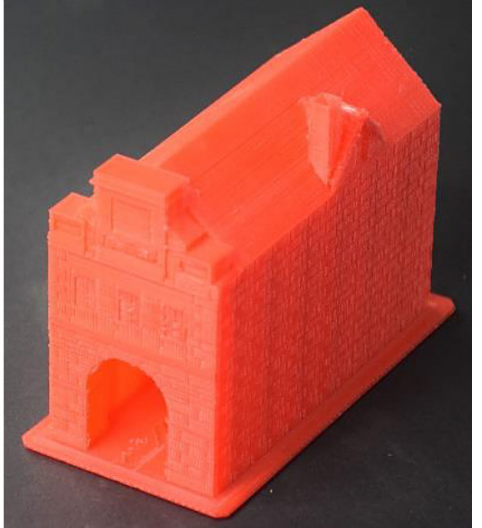

c)

Fig. 2. The Town Gate, condition from the 18th century, Lublin, Poland, the object printed in FFF technology: a) visible interior of the spatial structure stiffening the body of the model, b) raw model - visible supports, c) model after cleaning

century. The building was destroyed by several fires, and in the following centuries it was reconstructed and expanded many times by adding chapels (they function as aisles), a chancel and raising the tower. The present condition of the building dates back to the 19th century, Figure 3 and Figure 4.

The calculation of the scale of elements assigned to individual sub-models of the church shown in Figure 3 and Figure 4 is shown in Table 1. The selection of the appropriate scale allowed for the correct modelling process of an object dedicated to $3 \mathrm{D}$ printing. To make the model of the church, solid modelling was used with three different technologies for creating objects:
- by means of volumetric primitives and their editing (Boolean algebra operations - sum, difference, product were used for modification) - objects/elements of sub-model 1,

- for objects/elements belonging to sub-model 2 and sub-model 3 - using previously created $2 \mathrm{D}$ shape outlines, and then processing them into 3D objects:

- extrude - creates a 3D solid by extruding the contour of a closed 2D curve along a segment,

- sweep - allows to model a 3D solid by dragging a 2D closed curve along an appropriate open path (e.g. spline, arc),

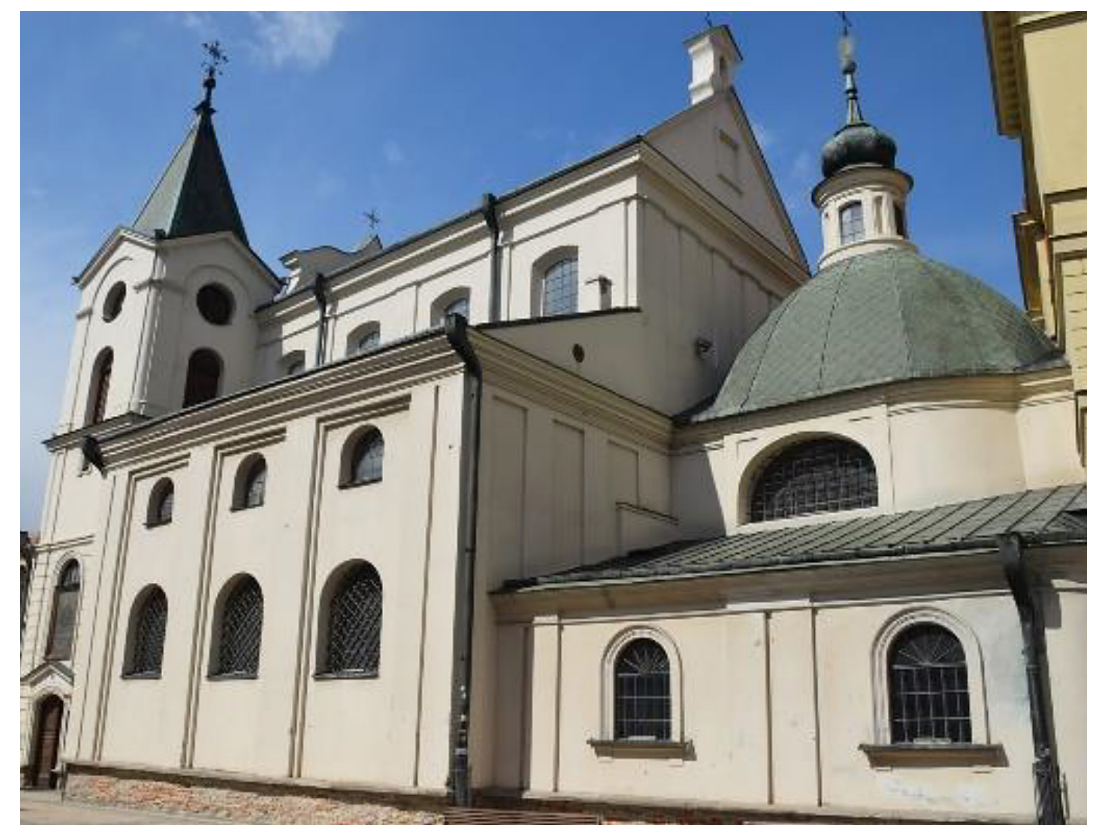

Fig. 3. Holy Ghost church, Lublin, Poland, state in the 19th century 


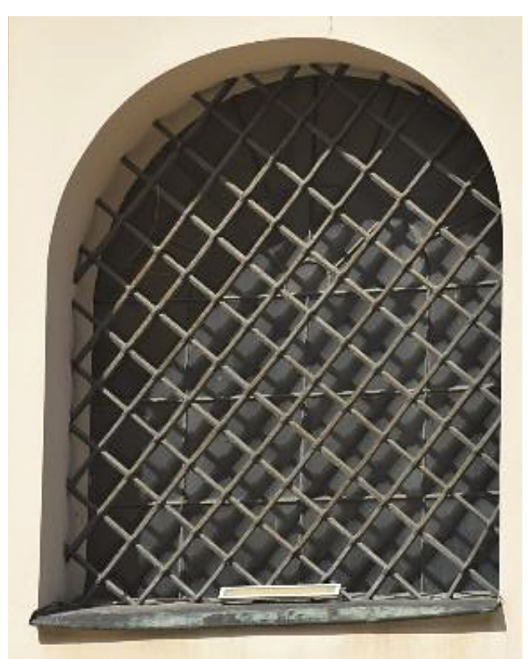

a)

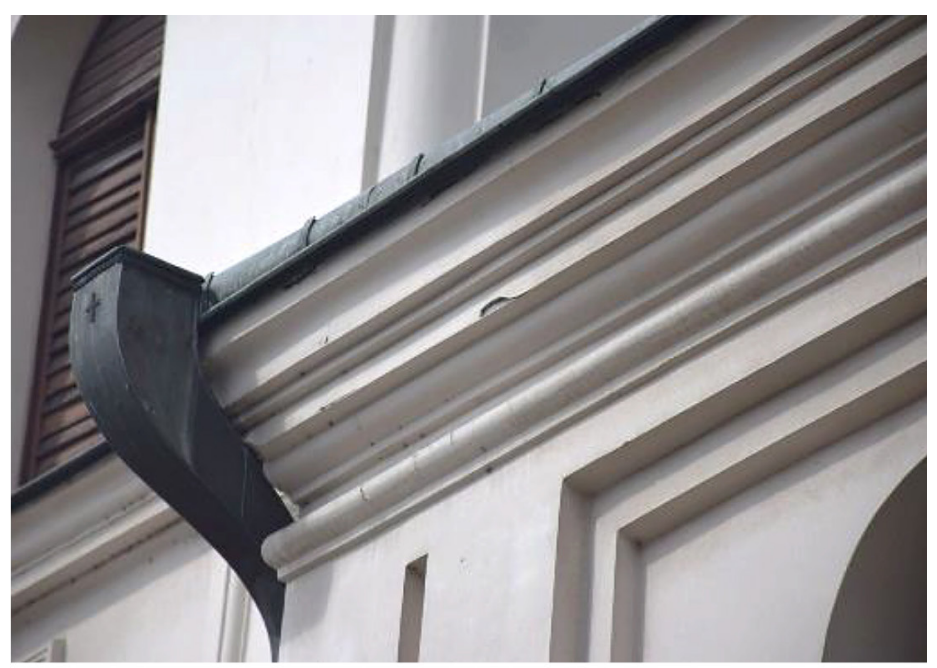

b)

Fig. 4. Holy Ghost church, Lublin, Poland: a) window and lattice in the window elements from sub-model 2 and sub-model 3, b) cornice - element from sub-model 3

Table 1. Holy Ghost church, Lublin, Poland. Scale selection for elements assigned to different sub-models for 3D modelling

\begin{tabular}{|c|c|c|c|c|c|}
\hline No. & $\begin{array}{c}\text { Sub- } \\
\text { model }\end{array}$ & Object/element & Actual dimensions [m] & $\begin{array}{l}\text { Dimensions of the model } \\
\text { after 3D printing [mm] }\end{array}$ & $\begin{array}{c}\text { Calculated } \\
\text { scale }\end{array}$ \\
\hline 1 & 1 & Body of the building & $35 \times 20 \times 22$ & $280 \times 160 \times 176$ & 125 \\
\hline 2 & 2 & $\begin{array}{l}\text { Window: } \\
\text { - width } \mathrm{x} \text { height } \\
\text { - recess depth }\end{array}$ & $\begin{array}{c}2.2 \times 3.5 \\
0.25\end{array}$ & $\begin{array}{c}17.6 \times 28.0 \\
4.2\end{array}$ & $\begin{array}{l}125 \\
60\end{array}$ \\
\hline 3 & 2 & $\begin{array}{l}\text { Portal: } \\
\text { - width } \mathrm{x} \text { height } \\
\text { - depth } \\
\end{array}$ & $\begin{array}{c}3.5 \times 4.0 \\
0.5\end{array}$ & $\begin{array}{c}28.0 \times 32.0 \\
8.3\end{array}$ & $\begin{array}{l}125 \\
60\end{array}$ \\
\hline 4 & 3 & $\begin{array}{l}\text { Window frame: } \\
\text { - width } \mathrm{x} \text { height } \\
\text { - thickness }\end{array}$ & $\begin{array}{c}2.2 \times 3.5 \\
0.1\end{array}$ & $\begin{array}{c}17.6 \times 28 \\
2\end{array}$ & $\begin{array}{l}125 \\
50\end{array}$ \\
\hline 5 & 3 & $\begin{array}{l}\text { Cornice: } \\
\text { - width } \\
\text { - height }\end{array}$ & $\begin{array}{l}0.21 \\
0.54\end{array}$ & $\begin{array}{l}3.5 \\
6.8\end{array}$ & $\begin{array}{l}50 \\
80\end{array}$ \\
\hline 6 & 3 & $\begin{array}{l}\text { Lattice in the window: } \\
\text { - mesh size } \\
\text { - bar thickness }\end{array}$ & $\begin{array}{c}0.12 \times 0.12 \\
0.02\end{array}$ & $\begin{array}{c}4 \\
1.3\end{array}$ & $\begin{array}{l}30 \\
15\end{array}$ \\
\hline 7 & 3 & Metal needle & 0.7 & 3 & 250 \\
\hline
\end{tabular}

- revolve - allows to create a 3D solid by dragging a $2 \mathrm{D}$ closed curve around the axis of rotation,

- loft - generates objects in the space between several sections made of closed 2D curves (e.g. ellipse, circle, polygon).

- by combining the above two techniques - objects/elements belonging to sub-model 2 and sub-model 3.

The three-dimensional modelling process of objects/elements assigned to the appropriate submodels is shown in Figure 5.
For elements of sub-model 2 and sub-model 3, non-proportional scaling was used (Table 1). This allowed for the correct reproduction of the details of these elements, as well as increasing their visibility and aesthetics. When creating a 2D cross-section of details, e.g. cornices (Fig. 6c), the lengths of the sections, their inclination angles and rounding were selected in such a way that no supports were created when printing them. The abovementioned activities have a positive impact on the $3 \mathrm{D}$ printing process itself, the correct $3 \mathrm{D}$ printing of the details of these elements and 
a)

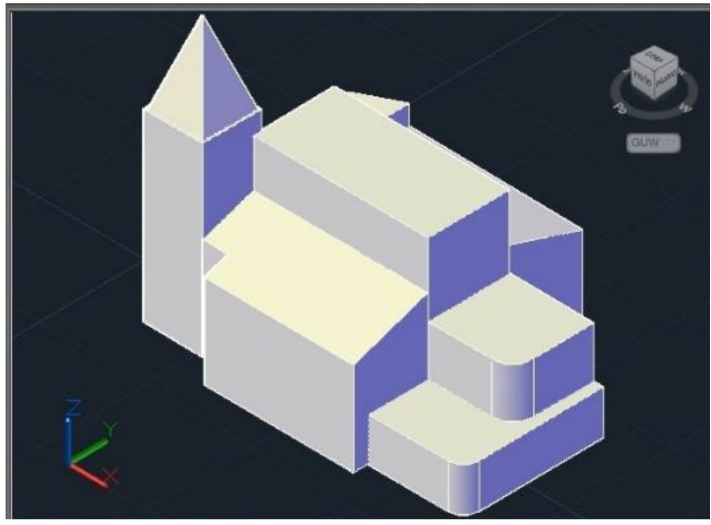

b)

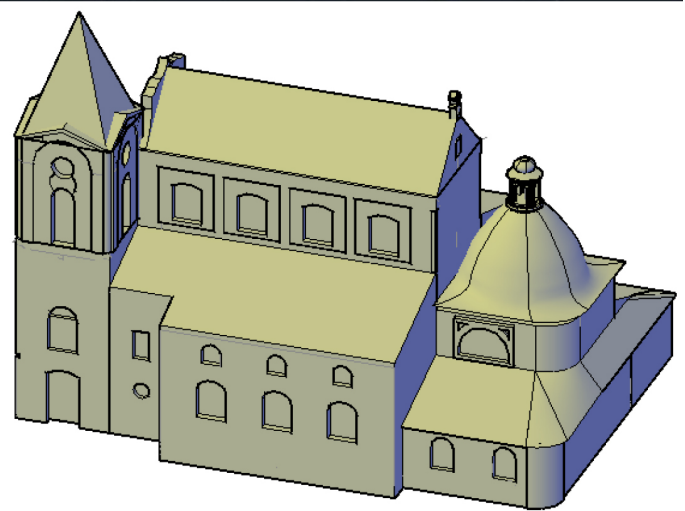

c)

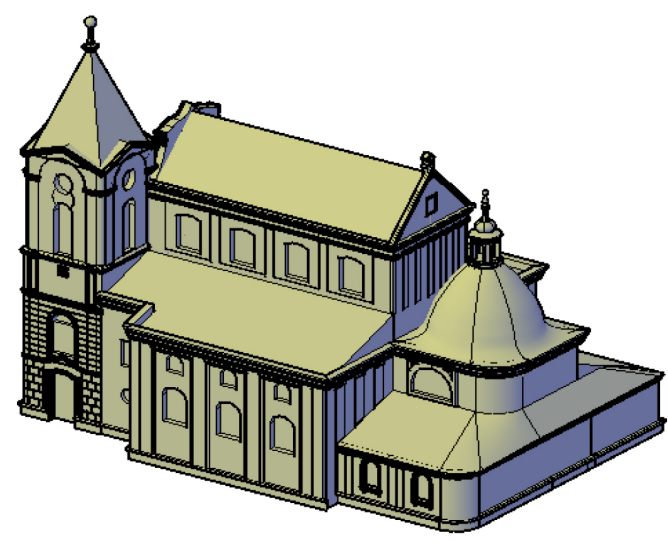

Fig. 5. Digital 3D model apperance: a) sub-model 1, b) sub-model 1 and submodel 2, c) sub-models 1, 2 and 3

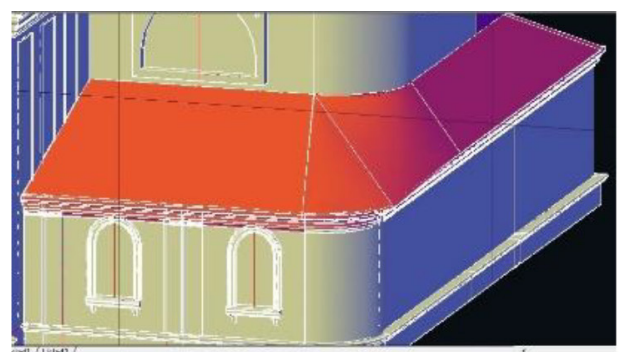

a)

their better visibility. Examples of 3D modelling of elements belonging to sub-models 2 and 3 are presented in Figure 6.

The virtual print model generated and the actual 3D model after cleaning are shown in Fig. 7 , and the results of the 3D printing simulation process are presented in Table 2.

\section{The three-dimensional model of St. Michael's church}

St Michael's church is an object that has not survived to our times. The first building was built at the beginning of the 14th century in the Gothic style and served as the city's temple. Despite many fires and damages, the building retained its original architectural style until the temple was demolished in the mid-nineteenth century due to the poor technical condition of the building. During its history, several chapels, a porch and sacristy were added to the church. In the Baroque period, the tower was covered with a Baroque dome, which can be seen in several preserved paintings. Examples of collected materials with plans, figures and the current state are presented in Figure 8.

For the reconstruction of the building, the state was chosen from the beginning of the 19th century, when the church tower was crowned with baroque lanterns, and not with an envelope roof as in Figure 8c. Solid modelling was selected from among the many different tools to prepare a digital 3D model (Fig. 9a). Due to the complex shape of the object consisting of many smaller objects - chapels, the available solid modelling primitives (e.g. cube, wedge, etc.) were used. Boolean operations (sum,

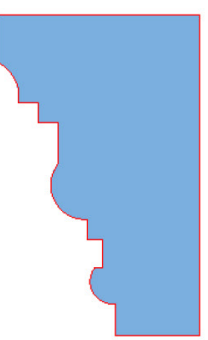

b)

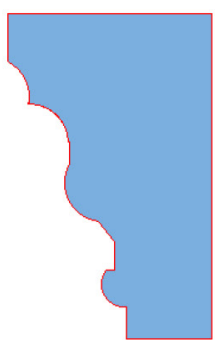

c)

Fig. 6. Digital modelling: a) sacristy at the presbytery - sub-model 2 , b) cornice - real 2D profile (see Fig. 4b), c) cornice - 2D profile after simplification (element from sub-model 3) 


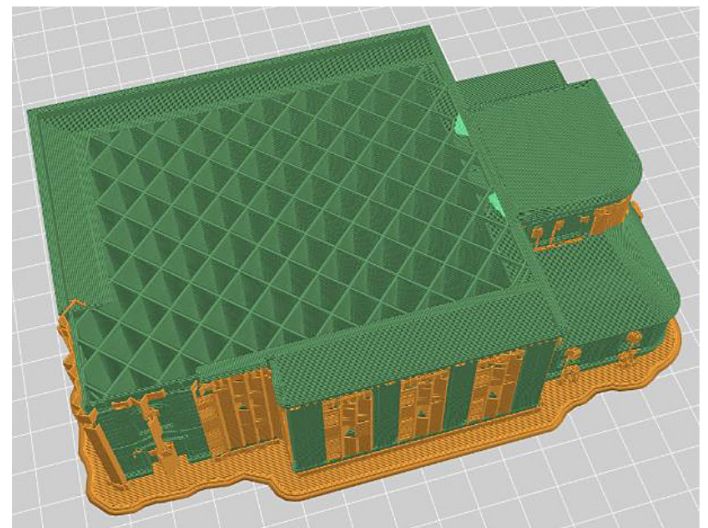

a)

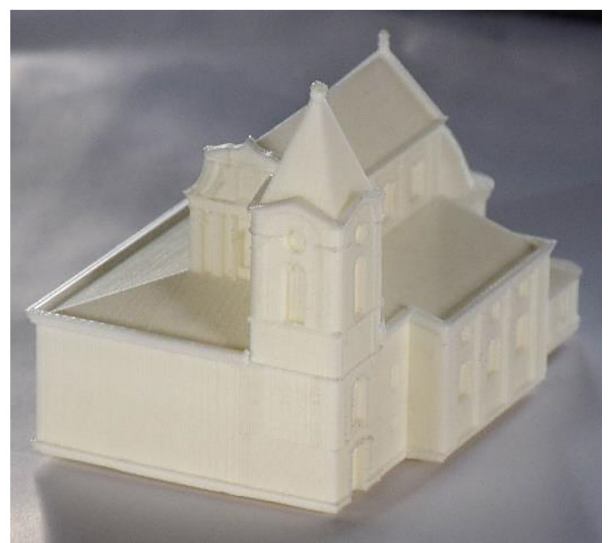

b)

Fig. 7. Holy Ghost church, Lublin, Poland: a) print simulation view in MakerBot Replicaton Z18 software, b) 3D model after removing the supports

Table 2. Parameters of 3D models and results of the 3D printing simulation process

\begin{tabular}{|l|c|c|c|c|}
\hline Model name & $\begin{array}{c}\text { Model dimensions } \\
{[\mathrm{mm}]}\end{array}$ & Size of the .stl file [kB] & $\begin{array}{c}\text { Estimated printing } \\
\text { time [h/min] }\end{array}$ & $\begin{array}{c}\text { Material } \\
\text { consumption [g] }\end{array}$ \\
\hline Holy Ghost church & $\begin{array}{c}\text { Length: } 143 \\
\text { Width: } 96\end{array}$ & 2048 & $18 / 02$ & 172.73 \\
\hline St Michael's church & $\begin{array}{c}\text { Length: } 140 \\
\text { Width: } 101\end{array}$ & 1630 & $22 / 09$ & 199.52 \\
\hline
\end{tabular}

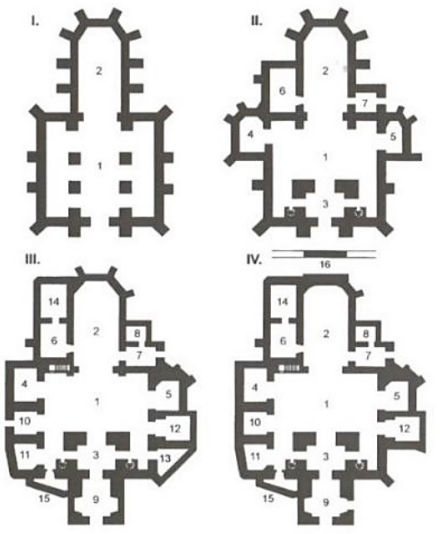

a)

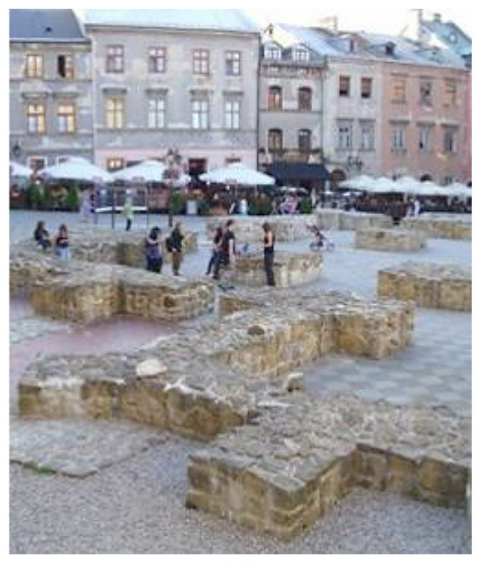

b)

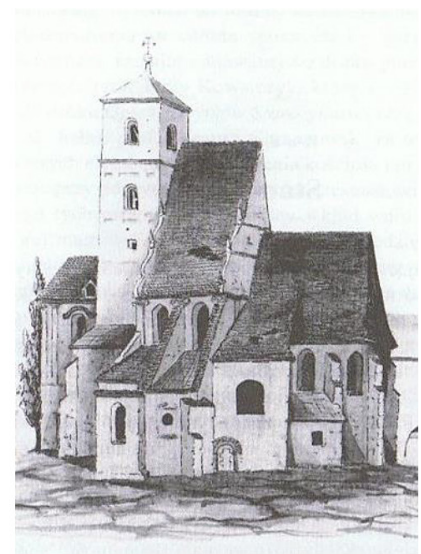

c)

Fig. 8. The non-existent church of St Michael, Lublin, Poland: a) the evolution of the building's plans from the 14th to the 19th century, b) ruins - state after conservation from the end of the 20th century, c) a drawing from 1844 before the building's demolition

difference, product) were used to edit solids. Objects belonging to individual sub-models described with the same scales were assigned to the same layers, thanks to which it was much easier to manage them. An additional base was designed for this model, which mainly strengthened the numerous buttresses placed in the corners of the chapels and the chancel (Fig. 9c). The printed model of the church after cleaning is shown in Figure $9 b$.

\section{The use of 3D printed models}

The prepared D3DMs of Lublin monuments were replicated in various scales, depending on their purpose. The obtained three-dimensional models became elements of an interactive board game with an automatic system for recognising the correctness of placing an object on the Lublin map board (using RFID readers) [26], Figure 10.

Moreover, they were used to conduct preliminary diagnosis (objects of various sizes were 


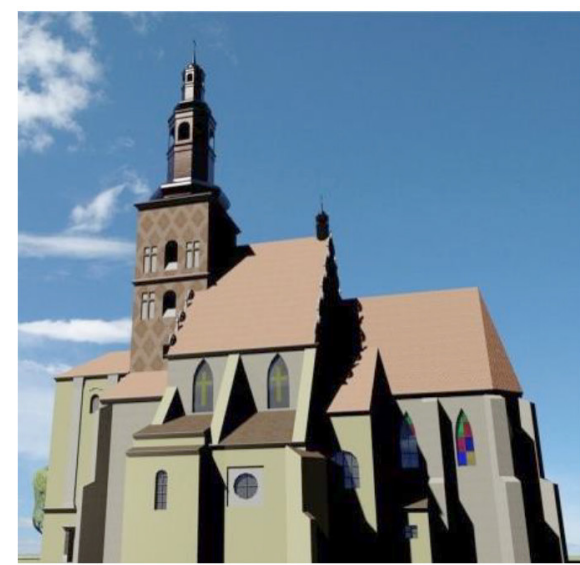

a)

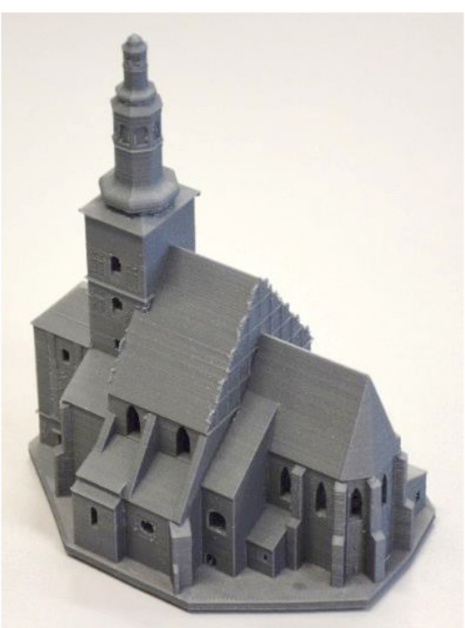

b)

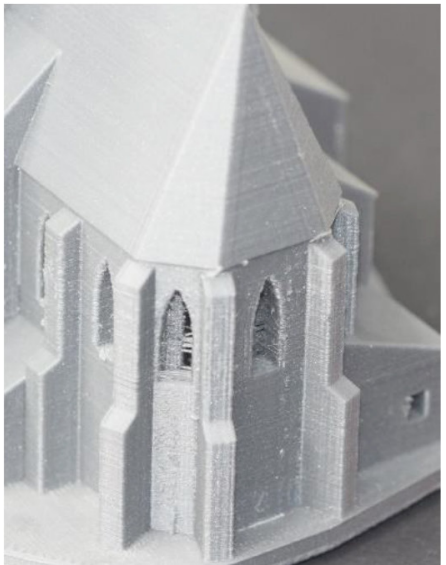

c)

Fig. 9. St Michael's Church, Lublin, Poland: a) photorealistic virtual model, b) 3D model printed in FFF technology, c) presbytery with buttresses

used) of their suitability for conducting classes with blind people, Figure 11a, and as objects for kinesthetic cognition, Figure 11b. As a side note, the authors of this paper have not yet found documented research on the effects of perception of models of architectural objects depending on the scaling method.

\section{CONCLUSIONS AND FUTURE WORK}

In the light of the results presented, it appears that the three-level procedure for creating digital 3D models of historic architectural objects

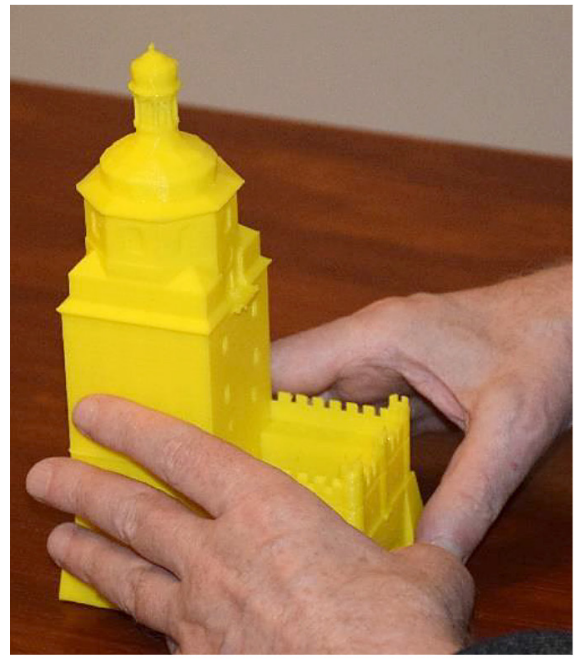

a)

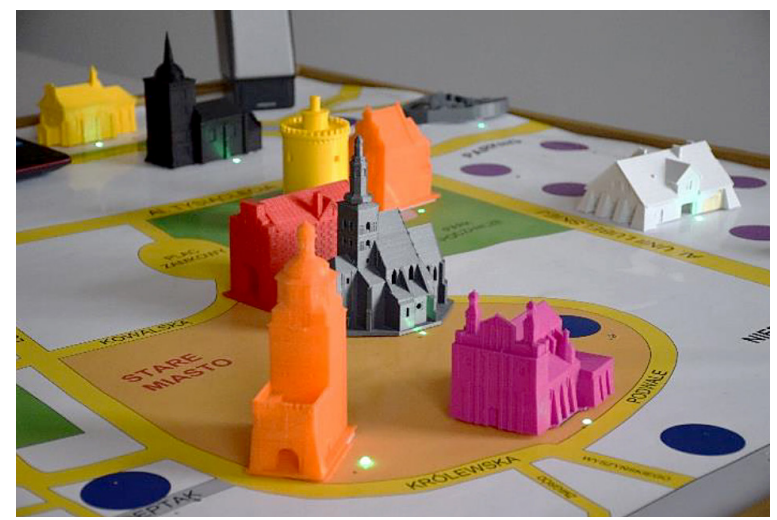

Fig. 10. 3D models of Lublin's architectural objects on the board of the game

"Architectural Jewels of Lublin"

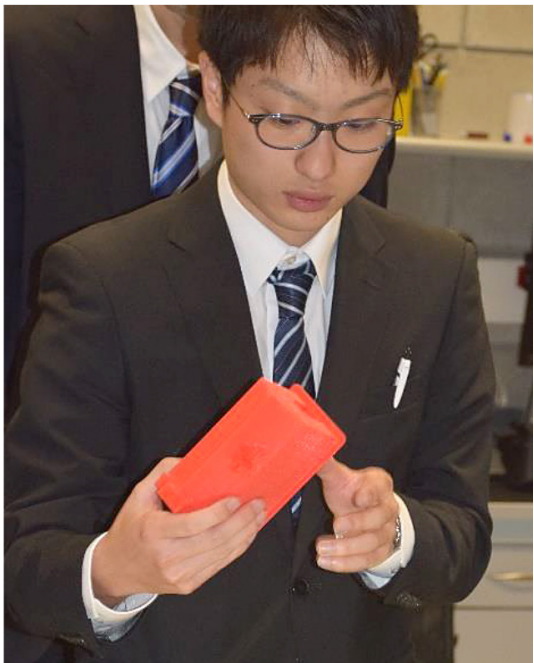

b)

Fig. 11. Kinesthetic cognition of real 3D models of architectural objects: a) a blind person - Cracow Gate, Lublin, Poland [6], b) a student from Japan looking at the Town Gate, Lublin, Poland 
presented in the paper, aimed at obtaining real copies of these objects by replication on 3D printers, is useful and may constitute a starting point for further standardisation of activities that will allow for increasing the efficiency of generating such 3D models.

The application at the second level of the procedure of decomposing the architectural elements of a historic object into elements belonging to defined sub-models ensured that the obtained 3D copies of real objects, despite the fact that they were made by many people, are characterised by well-selected scales of architectural details, which allowed them to be noticed and recognised, but without the effect of excessive exaggeration, and moreover, the repetition of the aesthetic impressions experienced by the subjects.

The use of modelling using a program based on parametric modelling (AutoCAD) and not a mesh modelling allowed to obtain models with very small file sizes. The created elements of the object were assigned to predefined layers, which significantly simplified the selection of their scales and their management in the 3D scene.

The prepared procedure allowed to generate 3D models that can be copied on 3D printers with limited scaling of the model as a whole, which allows for making copies for quite different purposes and increases the versatility of the proposed procedure.

The authors are convinced that in future works it will be possible to develop procedures in the AutoLisp language, which will significantly facilitate the definition of the scale of individual decorative and architectural elements and will contribute to the acceleration of the modelling process and optimisation of the appearance of the final printed copy.

\section{REFERENCES}

1. Nobayashi A., Rewiring Museum Information: Mobile and Cloud. N. Sonoda (ed.), New Horizons for Asian Museums and Museology, 2016: 89-96.

2. Quattrini R., Pierdicca R., Paolanti M., Clini P., Nespeca R., Frontoni E. Digital interaction with 3D archaeological artefacts: evaluating user's behaviours at different representation scales. Digital Applications in Archaeology and Cultural Heritage. 2020; 18: 1-36.

3. Barbieri L., Bruno F., Muzzupappa M. Virtual Museum System Evaluation Through User Studies. Journal of Cultural Heritage. 2017; 26: 101-108.
4. Bustillo A., Alaguero M., Miguel I., Saiz J.M., Iglesias L.S. A flexible platform for the creation of 3D semi-immersive environments to teach Cultural Heritage. Digital Applications in Archaeology and Cultural Heritage. 20015; 2: 248-259.

5. Rossetti V., Furfari F., Leporini B., Pelagatti S., Quarta A. Enabling Access to Cultural Heritage for the visualy impaired: an Interactive 3D model of a Cultural Site. The 9th International Conference on Ambient Systems, and Technologies (ANT 2018). Science Direct. Procedia Computer Science. 2018; 130: 383-391.

6. Montusiewicz J., Miłosz M., Kęsik J. Technical aspects of museum exposition for visually impaired preparation using modern 3D technologies. Proceedings of 2018 IEEE Global Engineering Education Conference (EDUCON). 2018: 774-779.

7. Williams T.L., "More than just a novelty? Museum visitor interactions with $3 \mathrm{D}$ printed artifacts," A thesis submitted in partial fulfillment of the requirements for the degree of Master of Arts University of Washington, 2017.

8. Rebuilding history with 3D printed architectural models; Leapfrog 3D Printers; https://www.lpfrg.com/testimonials/rebuilding-history-with-3dprinted-architectural-models; [access: 2021/03/28].

9. Visintini D., Spangher A., Fico B. The VRML model of Victoria Square in Gorizia (Italy) from laser scanning and photogrammetric 3D surveys. In Proceedings of the twelfth international conference on 3D web technology (Web3D '07). Association for Computing Machinery. 2007: 165-168.

10. Guidi G., Russo M, Angheleddu D. 3D survey and virtual reconstruction of archeological sites. Digital Applications in Archaeology and Cultural Heritage. 20014; 1: 55-69.

11. Miłosz M., Kęsik J., Montusiewicz J. 3D Scanning and Visualization of Large Monuments of Timurid Architecture in Central Asia - A Methodical Approach; ACM Journal on Computing and Cultural Heritage. 2021; 14(1): 1-31.

12. Hevko I., Potapchuk O., Lutsyk I., Yavorska V., Tkachuk V. Methods building and printing 3D models historical architectural objects. SHS Web Conf. The International Conference on History, Theory and Methodology of Learning (ICHTML 2020). 2020; 75: 1-6.

13. Parsinejad H., Choi I., Yari M. Production of Iranian Architectural Assets for Representation in Museums: Theme of Museum-Based Digital Twin, January 2021: 1-24, https://www.researchgate.net/ publication/348339148 [access: 2021/03/28].

14. Sanchez D. (nick: MiniWorld), Sioux Falls Cathedral - South Dakota, USA, MakerBot Thingivers; 2014; https://www.thingiverse.com/thing:550669 [access: 2021/03/28]. 
15. Grunewald S.J. Weekly Roundup: Ten 3D Printable Things - Architectural Wonders, Landmarks and Monuments. 3D Design3D, Printed Art, 3D Printing. May 20, 2016; https://3dprint.com/135048/103dplandmarks-monuments/; [access: 2021/03/28].

16. Çalışkan C.I, Reviving Ottoman bird palaces and retro approach with additive manufacting method. Digital Applications in Archaeology and Cultural Heritage. 2019; 14: 1-7.

17. Arsenault P.J. Using 3D Printers to Create Architectural Models; Continuing Education Center Architecure + Construction;

18. https://continuingeducation.bnpmedia.com/article print.php?C=1349\&L=448; [access: 2021/03/28].

19. Dong Q., Zhang Q., Zhu L. 3D scanning, modeling and printing of Chinese classical garden rockeries: Zhanyuan's South Rockery Heritage Science. 2020; 8(61): 1-15, doi: 10.1186/s40494-020-00405-z.

20. Correa F.R. Robot-Oriented Design for Production in the context of Building Information Modeling. 33 rd International Symposium on Automation and Robotics in Construction (ISARC 2016); Conference Paper, July 2016.

21. Tucci G., Bonora V. From Real to... "Real". A Review of Geomatic and Rapid Prototyping Techniques for Solid Modelling in Cultural Heritage Field. International Archives of the Photogrammetry, Remote Sensing and Spatial Information Sci- ences. 2011; XXXVIII-5/W16, ISPRS Trento 2011 Workshop, 2-4 March 2011, Trento, Italy.

22. Autodesk website: https://www.autodesk.com/ [access: 2021/03/28].

23. Monego M., Previato C., Bernardi L., Menin A., Achilli V. Investigating Pompeii: Application of 3D geomatic techniques for the study of the Sarno Baths. Journal of Archaeological Science: Reports 24 (2019): 445-462.

24. Wijnhoven M.A., Moskvin A. Digital replication and reconstruction of mail armour. Journal of Cultural Heritage. 45(2020): 221-233.

25. Rua H., Alvito P. Living the past: 3D models, virtual reality and game engines as tools for supporting archaeology and the reconstruction of cultural heritage - the case-study of the Roman villa of Casal de Freira. Journal of Archaeological Science. 2011; 30: 1-13.

26. Hajirasouli A., Banihashemi S., Kumarasuriyar A., Talebi S., Tabadkani A. Virtual reality-based digitisation for endangered heritage sites: Theoretical framework and application. Journal of Cultural Heritage p. 12, in press.

27. Milosz M., Montusiewicz J. The "Architectural Jewels of Lublin" Game as a Tool for Collaborative Interactive Learning of History. In: Auer M., Guralnick D., Simonics I. (eds) Teaching and Learning in a Digital World. ICL 2017. Advances in Intelligent Systems and Computing 715. Springer, Cham; 2018. 